\title{
Comments on the study comparing multiple stents and single stent insertion for chronic pancreatitis
}

We read with great interest the recently published study on comparing multiple stents and single stent insertion for pain relief in chronic pancreatitis (CP) [1]. The author concluded that treatment with a single stent was associated with better clinical outcome compared to treatment with exclusively two stents during the stenting period. However, we found some flaws in the study design that might have made the conclusion inaccurate.

First, there may be patient selection bias in terms of study design which caused the inconsistence of severity of distal stricture and painful episodes for patients underwent single stent or two stents insertion. Patients were retrospectively reviewed and divided into three groups according to number of stents insertion during the stenting period. Degree of distal stricture, frequency and number of painful episodes were not exhibited or compared among the three groups. Indeed, patients who were treated with two stents probably had more severe distal strictures or more severe and painful episodes before the stent insertion. Otherwise, why were these patients not treated with a single stent? As suggested in both the 2012 and 2018 European Society of Gastrointestinal Endoscopy (ESGE) guidelines for $\mathrm{CP}$, painful dominant main pancreatic duct strictures should be treated with a single plastic stent and multiple side-byside plastic stents can be considered when symptomatic main pancreatic stricture persists for more than 1 year after placement of the initial single plastic stent [2]. Therefore, patient selection bias caused the inconsistent distal strictures and painful episodes between patients treated exclusively with two stents and those treated with single stent, which probably led to bias in treatment outcome.
Second, there is a defect in the definition of clinical endoscopic treatment outcome. Patients in the study had continuous or recurrent pain with at least three painful episodes per year before endoscopic treatment. However, the authors did not provide detailed information on painful episodes. Endoscopic treatment outcome was simply defined according to Izbicki score (IS) at the end of the stenting period, with successful endoscopic treatment being defined as IS $\leq 10$ at the end of the stenting period. Besides IS, frequency and number of painful episodes also greatly affect patients and are critical indicators of quality of life, but they were ignored when evaluating treatment outcome. When defining the primary objective, outcome of endoscopic treatment, frequency and number of painful episodes should be considered.

In addition, the efficacy and safety of multiple plastic stents for refractory main pancreatic stricture in $C P$ has been underscored in the 2012 and 2018 ESGE guidelines and several prospective studies [2-5]. Use of multiple pancreatic stents has proven to be promising in achieving persistent stricture dilation on long-term follow-up in the setting of severe $C P$. Thus, the author should conduct rigorous studies to provide higher-quality evidence about the current conclusion or doubt may be cast upon it.

\section{Conclusion}

In conclusion, the design and definition of the primary objective in the current study could have been improved. Moreover, more stringent research should be done to verify the author's conclusion.

\section{Competing interests}

The authors declare that they have no conflict of interest.

The authors

Yu Liu*, Tao Zhang*', Zhao-Shen Li, Dan Wang, Liang-Hao Hu

Department of Gastroenterology, Changhai Hospital, The Second Military Medical University, Shanghai, China

\section{Corresponding author}

\author{
Liang-Hao Hu, MD \\ Department of Gastroenterology, The \\ Second Military Medical University; \\ Department of Gastroenterology, Changhai \\ Hospital, The Second Military Medical \\ University, 168 Changhai Road, Shanghai, \\ China \\ Fax: +86-21-55620081 \\ lianghao-hu@hotmail.com
}

\section{References}

[1] Papalavrentios L, Musala C, Gkolfakis P et al. Multiple stents are not superior to single stent insertion for pain relief in patients with chronic pancreatitis: a retrospective comparative study. Endosc Int Open 2019; 7: E1595-E1604

[2] Dumonceau JM, Delhaye M, Tringali A et al. Endoscopic treatment of chronic pancreatitis: European Society of Gastrointestinal Endoscopy (ESGE) Guideline - Updated August 2018. Endoscopy 2019; 51: 179-193

[3] Costamagna G, Bulajic M, Tringali A et al. Multiple stenting of refractory pancreatic duct strictures in severe chronic pancreatitis: long-term results. Endoscopy 2006; 38: 254-259

[4] Dumonceau JM, Delhaye M, Tringali A et al. Endoscopic treatment of chronic pancreatitis: European Society of Gastrointestinal Endoscopy (ESGE) Clinical Guideline. Endoscopy 2012; 44: 784-800

\footnotetext{
* These authors contributed equally.
} 
[5] Tringali A, Bove V, Vadala di Prampero SF et al. Long-term follow-up after multiple plastic stenting for refractory pancreatic duct strictures in chronic pancreatitis. Endoscopy 2019; 51: 930-935
Bibliography

DOI http://dx.doi.org/10.1055/a-1118-3563

Endoscopy International Open 2020; 08: E467-

E468

(c) Georg Thieme Verlag KG

Stuttgart · New York

eISSN 2196-9736

(c) (i) $\$$ 